\title{
ORIGINAL ARTICLE \\ Cervical spinal cord injury due to fall while carrying heavy load on head: a problem in Bangladesh
}

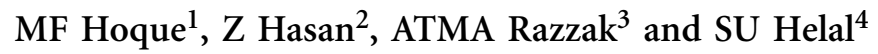

Study design: Observational study.

Setting: Centre for the Rehabilitation of the Paralysed (CRP), Dhaka, Bangladesh.

Methods: This observational study was conducted on 84 patients of Cervical spinal cord injury (CSCI) due to fall while carrying heavy load on head. They were admitted at the CRP, Dhaka, Bangladesh between January1999 and December 2001. Relevant personal information, neurological status, types of bony injuries and x-ray findings were noted down in pre-structured questionnaire. In addition, each subject was interviewed to find out the cause of accidental fall while carrying heavy load on head.

Results: Age of the studied subjects ranged between 10 to 50 years. All were male of whom 79 (94\%) subjects were farmers and/or low cost daily laborers. In all, $72 \%$ percent of the subjects were carrying $60-80 \mathrm{~kg}$ weight on their head when fall occurred. A total of $48(57 \%)$ subjects had complete neurological lesion. The most common vertebral levels were C5 and C6. So far the mechanism of injury is concerned hyper flexion of the cervical spine predominated (61\%) over hyperextension (36\%).

Conclusion: Fall while carrying heavy load on head is a common cause of $\mathrm{CSCl}$ in Bangladesh. The victims are mostly young farmers or unskilled day laborers who were not habituated to carry heavy load on head.

Spinal Cord (2012) 50, 275-277; doi:10.1038/sc.2011.153; published online 6 December 2011

Keywords: cervical spinal injury; load on head; fall

\section{INTRODUCTION}

Carrying heavy loads on the head is a common practice in Bangladesh and spinal injuries due to accidental fall while carrying such load is a public health problem in Bangladesh. ${ }^{1}$ The causes of spinal cord injury vary with age, sex, race and socio cultural activities in each population. ${ }^{2,3}$ During harvesting season the farmers and laborers in Bangladesh carry their products on their head and transport them from harvesting areas to local store houses or from one vehicle to another. Mahbub et al. ${ }^{4}$ showed that coolies of Bangladesh frequently carry a load weighing between $50-100 \mathrm{Kg}$.

Centre for the Rehabilitation of the Paralysed (CRP), a nongovernment organization in Dhaka, Bangladesh is a 100 bedded hospital involved in rehabilitation and management of patients with spinal cord injuries at a low cost. Patient care involves multi-disciplinary teams of doctors, nurses, physiotherapists, occupational therapists, social workers and vocational trainers, all of whom are specially trained for spinal cord injury management. It is the only center of this kind in Bangladesh, which admits referred patients from all over the country. Serving since 1990, the center is frequently admitting patients of cervical spinal cord injury (CSCI) with history of accidental fall while carrying heavy load on head. We have conducted a baseline study on those cases with an aim to identify the etiology and mechanism of injury. An understanding of the relevant aetiological factors should encourage the introduction of better methods of prevention.

\section{MATERIALS AND METHODS}

In total, 317 patients of CSCI were admitted at CRP, Dhaka, Bangladesh, between January 1999 and December 2001. Out of them 84 (26.45\%) had history of fall while carrying a heavy load on the head as shown in Table 1 . We have conducted an observational study on this 84 subjects starting from the day of their admission till discharge.

The subjects were interviewed to note down relevant personal information, how the accident occurred, type of object that was carried on head, approximate weight of carried load and the reason for the fall. A thorough clinical examination including determination of neurological status was performed. Types of bony injuries were determined by X-ray of cervical spine-AP, lateral and dynamic views (when necessary). All information was noted down in pre-structured questionnaire. ASIA impairment scale (AIS) was used for assessment of neurological status. ${ }^{5}$ Mechanism of injury was determined by patient's history, clinical profile and X-ray findings. MRI and CT scan were not performed because of nonavailability of the facilities. Most of the patients received conservative management with a Gardner-Wells skull tong traction in a Styker frame at least for 6 weeks. Only six cases underwent surgical decompression and fusion.

\section{RESULTS}

This study on 84 subjects with CSCI due to fall while carrying heavy load on head shows that all were males. The age of most of them (95\%) were 40 or less (Table 2). A total of 79 (94\%) patients were farmers and/ or laborers and the rest $(6 \%)$ were students and service holders and none of them were regular load carrier. The goods carried on head included harvest materials, such as sacks of potato, rice, crops, fruits,

\footnotetext{
${ }^{1}$ Department of Orthopaedics and Spinal surgery, Square Hospital, Dhaka, Bangladesh; ${ }^{2}$ Department of Microbiology, Square Hospital, Dhaka, Bangladesh; ${ }^{3}$ Centre for the Rehabilitation of the Paralysed (CRP), Dhaka, Bangladesh; ${ }^{4}$ Centre for the Rehabilitation of the Paralysed (CRP), Dhaka, Bangladesh

Correspondence: Dr MF Hoque, Department of Orthopaedics and Spinal surgery, Square Hospital, 18/F Bir Uttam Qazi Nuruzzaman Sarak (West Panthapath), Dhaka 1205, Bangladesh.

E-mail: fazlul@squarehospital.com

Received 26 July 2011; revised 3 November 2011; accepted 4 November 2011; published online 6 December 2011
} 
Table 1 Causes of cervical spinal cord injuries in Bangladesh

\begin{tabular}{llr}
\hline Causes & No. & $\%$ \\
\hline Fall while carrying a heavy load on the head & 84 & 26.4 \\
Road traffic accidents & 76 & 23.9 \\
Falling from a height & 57 & 17.9 \\
Fall of a heavy object onto the head or neck & 52 & 16.4 \\
Bull attack & 14 & 4.4 \\
Diving into shallow water & 11 & 3.4 \\
Others: (assault, cut throat injury, gunshot injury & 23 & 7.2 \\
and slip on the ground) & &
\end{tabular}

Table 2 Age distribution of studied subjects $(n=84)$

\begin{tabular}{lcc}
\hline Age of the patients & No. of patients & $\%$ \\
\hline $10-19$ years & 15 & 17.8 \\
$20-40$ years & 65 & 77.4 \\
$41-50$ years & 4 & 4.7 \\
Total & 84 & 100 \\
\hline
\end{tabular}

vegetables and fertilizers. Around three quarter (72\%) of the victims were carrying loads of standard size weighing between 50 to $100 \mathrm{~kg}$ on their head at the time of fall. The rest of the victims (28\%) were carrying miscellaneous items of non-standard size and the exact weights could not be guessed by the investigator. However, the description of the load mentioned by the victim suggested that it would be above $50 \mathrm{Kg}$. Neurological level revealed that C4 was involved in $76(90.4 \%)$ patients. So far the bony injury was concerned C5 and C6 were most commonly (47; 56\%) affected skeletal levels (Table 3). Complete neurological lesion (AIS A) was found in $48(57 \%)$ and incomplete lesion (AIS B, C and D) in 33 (39\%) subjects. Only 3 (4\%) subjects had spinal injury without any neurological deficit. No neurological recovery was observed among patients with complete lesion during discharge. However, recovery of varying degrees was observed among subjects with incomplete lesion. Duration of stay in the hospital ranged between 1 to 9 months with an average of 4 months.

More than half $(60 \%)$ of the accidental falls occurred in farmland or muddy paths. The rest (40\%) occurred while transporting goods from one vehicle or storehouse to other through a narrow and sloping surface (Figure 1). Hyper flexion injuries $51(61 \%)$ occurred more frequently than hyper extension injuries 30 (36\%). Rest (3\%) was twisting injury.

In all, $11(13 \%)$ subjects developed catheter associated urinary tract infection and $17(20 \%)$ had pressure sore during their stay in the center. Two patients died of respiratory complications and remaining 82 were sent home after rehabilitation and vocational training.

\section{DISCUSSION}

Only a few literatures on effect of carrying heavy loads on head in developing countries are available. Echarri et al. ${ }^{6}$ who have studied on firewood carriers of women of Congo found that carrying load on head for prolonged period lead to degenerative changes in the cervical spine. Mahbub et al. ${ }^{4}$ also identified the presence of cervical spondylosis and musculoskeletal symptoms among the professional load carriers in a city of Bangladesh. However, we did not notice marked degenerative changes of cervical spine among our subjects though they were carrying heavy loads weighing more than $50 \mathrm{~kg}$. The reason for absence of any remarkable degenerative changes could be that, most of them were non-habitual weight carriers and young with age ranging between 10-40 years.
Table 3 Level of vertebral injury

\begin{tabular}{lrr}
\hline Level of injury & No. & $\%$ \\
\hline C-2 & 15 & 17.8 \\
C-3 & 7 & 8.3 \\
C-4 & 5 & 5.9 \\
C-5 & 25 & 29.7 \\
C-6 & 22 & 26.2 \\
C-7 & 10 & 11.9 \\
Total & 84 & 100 \\
\hline
\end{tabular}

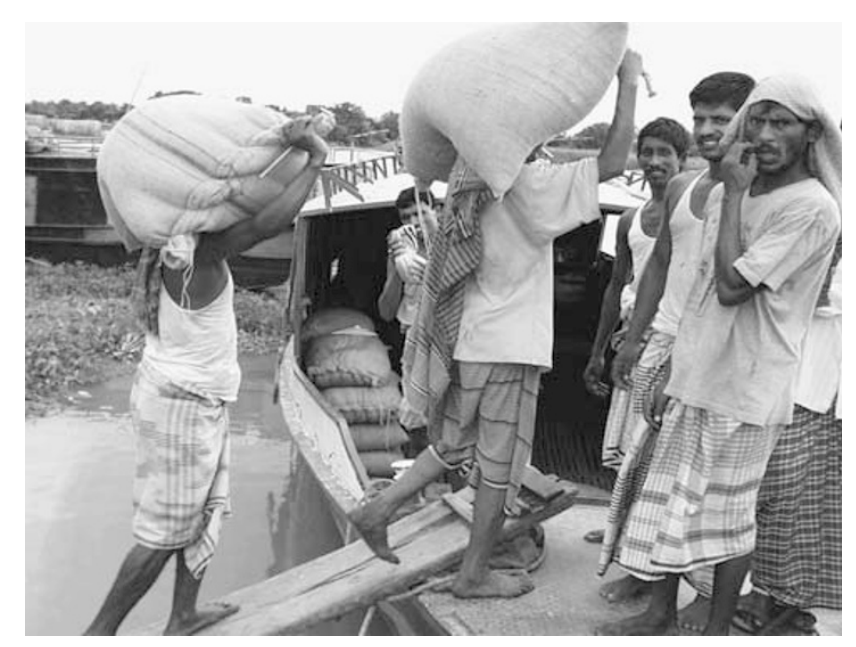

Figure 1 Typical picture of Bangladeshi laborers carrying heavy load on head.

At the time of accidental fall most of our subjects were carrying harvested materials. The heavy load they were carrying did not directly cause the injury. It was the accidental fall coupled with the force of the heavy load that lead to hyper flexion or hyper extension of spinal column that caused the damage. While walking downhill in a slope, the weight of the heavy load would incline forward forcing the carrier to move faster. In this critical situation if, by any reason, he loses his balance, sudden hyperflexion of neck would occur. On the other hand, while walking uphill, the head would be inclined backward causing hyperextension. In rural settings the surfaces/paths were nearly always sloped and uneven. After rain the roads/paths became very muddy and slippery too. As the subject carrying the load had to keep his neck erect all the time, it was difficult for him to observe on which surface he was walking. In above situations, as the load was too heavy for him, the subject was unable to shake it off from his head during the fall. From detailed interview with the subjects it was clear that when fall was imminent because of sudden loss of balance, they tried (by reflex) to shake off the load from their head. Unfortunately they failed to do so because the load was too heavy for them. The literatures also suggest that hyperflexion and hyperextension are the major mechanisms of CSCI. ${ }^{7,8}$ However, in a few cases twisting of the neck was the reason for cervical injury. According to Roaf et al., ${ }^{9}$ certain degree of rotation also occurs during hyper flexion.

Because of the relatively poor mechanical stability, the cervical spine is more vulnerable to trauma than the other areas of vertebral column. ${ }^{10}$ Our radiological reports reveal that C5 and C6 were the most common skeletal level. Other studies also show similar findings. ${ }^{111-15}$ Interestingly, we observed that though radiological injury was found in C5 and C6 vertebral level, in many of these cases clinically C4 was their actual neurological level. Possible explanation for this finding could be that the secondary damage to spinal 
cord occurred because of mal-handling by untrained attendants who carried the victim from place of accident to a nearby hospital. Moreover, the local transports were not conducive of carrying such patients in safe manner.

Associated injuries such as fracture of other bones, abrasions and lacerations of soft tissues were not mentioned in this study. The reason is that most of the patients received their initial treatment elsewhere in local hospitals and later they were referred to this center for rehabilitation.

\section{CONCLUSION}

It may be concluded that fall while carrying heavy load on head is a common cause of CSCI in Bangladesh. The victims were mostly young farmers or day laborers who were not habituated to carry heavy loads on head. The injury occurred mostly owing to hyper-flexion of the neck and $\mathrm{C} 5$ and $\mathrm{C} 6$ were the commonest levels of injury. We recommend the introduction of an awareness-building program among them to prevent such accidents.

\section{DATA ARCHIVING}

There were no data to deposit.

\section{CONFLICT OF INTEREST}

The authors declare no conflict of interest.

\section{ACKNOWLEDGEMENTS}

The authors express their gratefulness to Valerie A Taylor, the founder and coordinator of Centre for the Rehabilitation of the Paralysed (CRP), Dhaka, Bangladesh.
1 Hoque MF, Grangeon C, Reed K. Spinal Cord Lesion in Bangladesh: epidemiological study 1994-1995. Spinal Cord 1999; 37: 858-861.

2 Kennedy E, Stover S, Fine P (eds) Spinal Cord Injury: The Facts and Fingers. The University of Alabama Spinal Cord Injury Statistical Center: Birmingham, AL.

3 Grundy D, Swain A. At the accident. In: ABC of Spinal cord Injury, 3rd ed. BMJ Publishing Group: London, 1996, p 64

4 Mahbub MH, Laskar MS, Sheikh FA, Altaf MH, Inoue M, Yokoyama K, Wakui T, Harada N. Prevalence of cervical spondylosis and musculoskeletal symptoms among coolies in a city of Bangladesh. J Occup Health 2006; 48: 69-73.

5 Ditunno JF, AA Young WH, Donovan WH, Creasy G. The international standards boooklet for neurological and functional classification of spinal cord injury. Paraplegia 1994; 32: 70-80.

6 Echarri JJ, Forriol F. Effect of axial load on the cervical spine: a study of Congolese woodbearers. International Orthopaedics (SICOT) 2002; 26: 141-144.

7 Fukushima M, Kaneoka K, Ono K, Sakane M, Ujihashi S, Ochiai N. Neck injury mechanism during direct face impact. Spine 2006; 31: 903-908.

8 Marar BC. Hyperextension injuries of the cervical spine. J Bone J Surg 1974; 56-A: 1655-1662.

9 Roaf R. A study of the mechanics of spinal injuries. J Bone Joint Surg 1960; 42-B: 810-823.

10 Meyer P. Surgical stabilization of cervical spine. Surg Spinal Trauma. Churchill Livingstone: New York, 2011, pp 315-316.

11 Yoganandan N, Haffner M, Dennis JM, Nichols H, Steven SW, Standford JL et al. Epidemiology and Injury Biomechanics of Motor vehicle related trauma to the human spine. Proceedings of the 33rd Stapp Car Crash Conference SAE paper \#892438, 1989, pp 223-224.

12 Portnoy HD, McElhaney JH, Melvin JW, Croissant PD. Mechanism of cervical spine injury in auto accidents. Proceedings of the 15th conference of the American Association for Automotive Medicine 1972, pp 58-83.

13 Go BK, DeVivo MJ, Richards JS. The epidemiology of spinal cord injury. In: Stover SL, DeLisa JA, Whiteneck GG (eds) Spinal Cord Injury: Clinical Outcomes from the Model Systems. Aspen publishers: Gaitersburg, MD, 1995, pp 21-55.

14 Burke DC, Burley HT, Ungar GH. Data on spinal injuries- Part 1. Collection and analysis of 352 consecutive admissions. Austr NZ J Surg 1985; 55: 3-12.

15 Prasad VSSV, Schartz A, Bhutani R, Sharkey PW, Schwartz ML. Characteristics of injuries to the cervical spine and spinal cord in polytrauma patient population: experience from a regional trauma unit. Spinal Cord 1999; 37: 560-568. 